\title{
Meningkatkan Kesehatan Mental Penderita Diabetes Melitus di Komunitas dengan Kegiatan Kelompok Swabantu (Self Help Group)
}

\section{Improving the Mental Health of Diabetes Mellitus Suspects with Self Help Group in Community}

\author{
Tesaviani Kusumastiwi ${ }^{1}$, Lilis Suryani ${ }^{2}$, Denny Anggoro P. ${ }^{3}$ \\ ${ }^{1,2,3}$ Fakultas Kedokteran dan Ilmu Kesehatan \\ Universitas Muhammadiyah Yogyakarta, Bantul, Daerah Istimewa Yogyakarta \\ ${ }^{2}$ Pusat Studi Wanita Universitas Muhammadiyah Yogyakarta \\ 1tesaviani.kusumastiwi@gmail.com, ${ }^{2}$ lilis fkumy@yahoo.co.id, \\ 3denny7fkumy@yahoo.com
}

Riwayat Artikel: Dikirim 25 Januari 2019; Diterima 7 Mei 2019; Diterbitkan 31 Mei 2019

\begin{abstract}
Abstrak
Diabetes melitus merupakan penyakit metabolik yang memiliki prevalensi yang cukup tinggi di Indonesia. Penanganan jangka panjang pada penyakit ini dapat memberikan beban baik fisik maupun mental pada penderitanya. Munculnya masalah kesehatan mental pada pasien diabetes melitus akan memperburuk prognosis pasien. Penanganan holistik baik fisik dan mental diharapkan dapat dilakukan pasien diabetes melitus, salah satunya melalui kelompok swabantu (self help group) yakni kelompok yang terdiri dari para penderita diabetes melitus yang saling berbagi permasalahan dan memberikan dukungan satu sama lain. Program pengabdian masyarakat kelompok swabantu penderita diabetes mellitus dilaksanakan di Desa Bogoran, Trirenggo, Bantul. Kegiatan swabantu berisi tentang sharing dari masing-masing penderita yang dipantau/dimonitor oleh dokter ahli jiwa. Pada kelompok swabantu di Desa Bogoran, Trirenggo, Bantul ditemukan komorbiditas gejala klinis depresi dan cemas pada penderita diabetes. Beberapa permasalahan yang dialami oleh para penderita adalah manajemen stres, gangguan tidur, kepatuhan minum obat, ketakutan akan komplikasi dan penyesuaian gaya hidup. Kegiatan kelompok swabantu selain dapat membantu para penderita diabetes dalam menangani permasalahan yang dihadapi terkait dengan diabetes melitus, juga dapat memberikan rasa kebersamaan dan saling menguatkan antar penderita diabetes.
\end{abstract}

Kata kunci: diabetes melitus, kelompok swabantu, kesehatan mental

\begin{abstract}
Diabetes mellitus is a metabolic disease that has a high prevalence in Indonesia. Long-term treatment of this disease can provide physical and mental burden on the sufferer. The emergence of mental health problems in patients with diabetes mellitus will worsen the patient's prognosis. Holistic handling both physically and mentally is expected to be carried out by patients with diabetes mellitus, one is through self-help groups (self-help group), which is a group consisting of people with diabetes mellitus who share problems and provide support for each other. The community service program for self-help groups with diabetes mellitus was carried out in Bogoran Village, Trirenggo, Bantul. Self-help activities are about sharing from each sufferer who is monitored by a psychiatrist. In the selfhelp group in the Bogoran Bantul area, comorbid clinical symptoms of depression and anxiety were found in diabetics. Some of the problems experienced by sufferers are stress management, sleep disorders, compliance with medication, fear of complications and lifestyle adjustments. Self-help group activities besides being able to help diabetics in dealing with problems faced with diabetes mellitus, they can also provide a sense of togetherness and mutual support among diabetics.
\end{abstract}

Keywords: diabetes mellitus, self-help groups, mental health

\section{PENDAHULUAN}

Diabetes melitus (DM) merupakan salah satu penyakit metabolik yang banyak dijumpai, yakni dengan prevalensi $4 \%$ di seluruh dunia (Anani, 2012). Di Indonesia, jumlah penderita diabetes melitus menempati peringkat pertama di Asia Tenggara yakni 8.426.000 jiwa pada tahun 2000 (Ariani, 2012). Angka tersebut diprediksi akan terus meningkat hingga 21.3 
juta jiwa pada tahun 2030. Yogyakarta merupakan salah satu provinsi dengan angka prevalensi tertinggi yakni $2.6 \%$ bila dibandingkan dengan provinsi lainnya (Anani, 2012). Salah satu yang menyumbang angka tinggi diabetes melitus adalah dari kabupaten Bantul.

Diabetes melitus merupakan penyakit yang bersifat kronik (jangka panjang) sehingga menimbulkan beban baik secara fisik maupun psikologis. Dampak psikologis yang dialami oleh penderita diabetes melitus dapat berupa respon emosional negatif terhadap penyakit yang diderita, pengobatan jangka panjang, maupun disfungsi diberbagai aspek kehidupan (SobolPacyniak et al., 2014). Hal tersebut menimbulkan dampak pada kesehatan mental bagi penderita. Dua komorbiditas kesehatan mental terbanyak pada penderita diabetes melitus adalah berupa depresi dan kecemasan (Balhara dan Sagar, 2011). Hal ini didukung dengan data $2 / 3$ pasien diabetes melitus memiliki komorbiditas dengan depresi (Katon, 2008). Adanya komplikasi kesehatan mental, baik berupa cemas maupun depresi pada diabetes melitus dapat memperburuk prognosis pada pasien. Adanya aktifitas fisik yang menurun dan kepatuhan minum obat yang menurun akibat kesehatan mental juga dapat meningkatkan kadar lipid dan memperburuk prognosis diabetes melitus (Taylor et al., 2005). Dalam menyelesaikan permasalahan penanganan holistik bagi penderita penyakit kronis, salah satunya dapat digunakan metode kelompok swabantu atau self help group. Metode ini telah dilakukan sebelumnya dan terbukti membantu pasien dalam mengenali emosi, penyakit maupun membantu pasien dalam merawat dirinya sendiri. Pasien yang masuk dalam kelompok swabantu memiliki semangat yang lebih dalam menjalani pengobatan, kepatuhan minum obat maupun jadwal kontrol (Tejada-Tayabas, dan Lugo, 2014).

Serupa dengan penelitian sebelumnya, penelitian Kelleher et al. (1991), mengatakan bahwa kelompok swabantu membantu para pasien penyakit kronis dalam bertukar pengalaman dalam menghadapi penyakit. Penelitian lain menunjukkan adanya penurunan tingkat depresi dan cemas setelah menjalani perlakuan kelompok swabantu (Seekles et al., 2011). Dalam pengabdian ini akan dilakukan penanganan kesehatan mental pasien diabetes menggunakan metode kelompok swabantu. Melalui metode ini, para penderita dapat dikumpulkan pada satu tempat dan saling menyampaikan permasalahannya. Kehadiran para penderita dapat menguatkan satu sama lain dan saling membantu serta bertukar informasi dalam mengatasi problem terkait diabetes melitus yang dialami anggotanya.

\section{METODE}

\section{Peserta}

Peserta kegiatan adalah penderita diabetes melitus di Desa Bogoran, Trirenggo, Bantul. Penderita. Peserta dikumpulkan oleh kader kesehatan yang berada di desa Bogoran dan didapatkan 9 peserta yang telah dijelaskan dan bersedia mengikuti kegiatan hingga berakhir

\section{Pelaksanaan}

Dilakukan kegiatan penyuluhan mengenai diabetes melitus dan dampak bagi kesehatan mental kepada peserta dan caregiver. Dalam kegiatan tersebut dilakukan rekruitment peserta. Sebelum pelaksanaan kelompok terapi swabantu dilakukan skrining kesehatan jiwa menggunakan instrumen HADS dan dilakukan review penerapan kelompok swabantu setelah kegiatan swabantu berakhir. 
Gambar 1.

Sosialisasi Penyakit Dibetes Melitus di Desa Bogoran, Trirenggo, Bantul
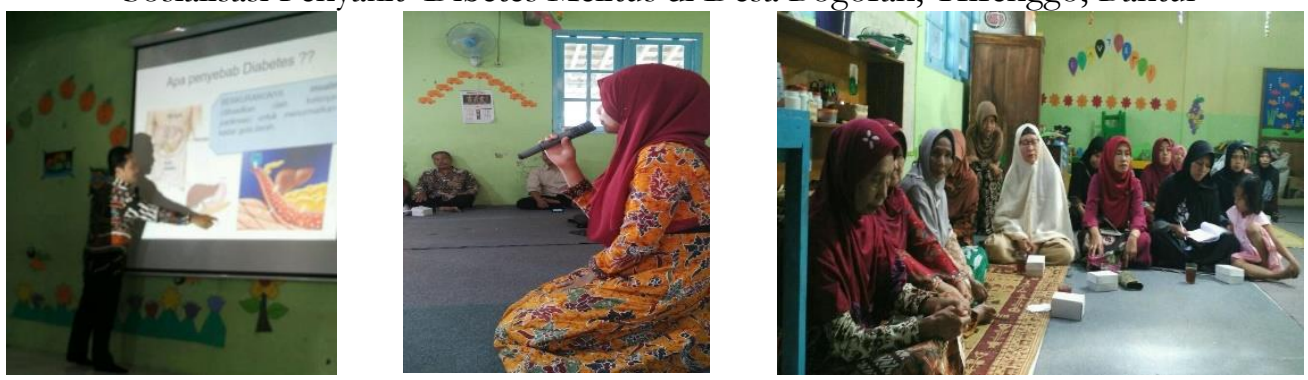

Sumber: Dokumen Pribadi

\section{HASIL DAN PEMBAHASAN}

Pada kegiatan ini diikuti peserta dengan karakteristik demografik laki-laki 33\%, perempuan 66\%. Rata-rata usia peserta kegiatan kelompok swabantu adalah 54.22 tahun. Rata-rata peserta telah mengidap diabetes melitus selama 3.5 tahun. Hasil pemeriksaan menggunakan instrumen HADS didapatkan skor borderline cemas sebanyak $44.4 \%$, skor gangguan klinis cemas sebanyak $22.2 \%$. Hasil pemeriksaan menggunakan instrumen HADS didapatkan skor borderline depresi sebanyak $22.2 \%$, sedangkan skor gangguan klinis depresi sebanyak $66.1 \%$.

Pada sesi kelompok swabantu didapatkan 5 topik permasalahan. Permasalahan tersebut antara lain mengenai manajemen stres, kesulitan tidur, mengatasi rasa bosan dalam pengobatan, mengatasi ketakutan akan komplikasi dan cara menyesuaian diri dengan diabetes melitus. Pada topik manajemen stres, hampir semua peserta memiliki permasalahan yang sama, yakni ketika sedang memiliki masalah dalam hidupnya maka badan terasa tidak nyaman dan saat di periksa terjadi peningkatan gula darah. Beberapa solusi disampaikan peserta terkait masalah yang dialami, antara lain mencoba mengalihkan pikiran dengan kegiatan lain seperti berolahraga, memasak, mengaji, maupun bersosialisasi. Ada pula peserta yang menyampaikan bila dirinya sudah mulai mengurangi aktivitas agar tidak banyak masalah yang dihadapi.

Pada topik sulit tidur, tidak semua peserta mengalami keluhan yang sama. Dari 9 peserta, hanya 3 orang yang menyampaikan keluhan sulit tidur di malam hari. Melalui 3 orang peserta yang pernah mengalami keluhan yang sama, disampaikan cara mengatasi keluhan sulit tidur, antara lain menggunakan waktu saat tidak dapat tidur dengan aktivitas lain. Peserta lain menyampaikan bahwa saat dirinya sulit tidur, biasanya disebabkan oleh gula darah tinggi, sehingga peserta menyampaikan saran untuk memastikan gula darah terkendali. Peserta lain menyampaikan pengalamannya untuk mengatasi sulit tidur dengan cara mengurangi tidur di siang hari.

Gambar 2.

Kegiatan Swabantu di Desa Bogoran

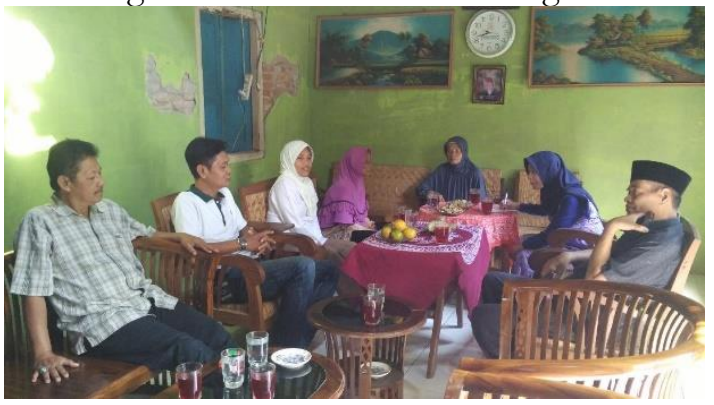

Sumber: Dokumen Pribadi

Topik yang dibahas selanjutnya adalah mengatasi rasa bosan minum obat. Hampir semua peserta mengalami rasa bosan dalam minum obat. Beberapa menyampaikan keluhan yang sama dan sampai saat ini masih sering merasakan bosan dalam minum obat. Biasanya para peserta akan kembali rajin minum obat setelah merasakan rasa yang tidak nyaman pada tubuhnya, misalkan mulai pandangan kabur, sakit kepala atau kesemutan. Beberapa peserta telah mengerti bila 
pengobatan diabetes bersifat jangka panjang, namun belum memiliki penyelesaian dalam problem kepatuhan minum obat. Topik selanjutnya ialah mengalami ketakutan akan komplikasi dari diabetes melitus. Tidak semua peserta mengalami ketakutan akan komplikasi. Namun beberapa saran yang diberikan adalah rutin memeriksakan diri ke dokter dan mempercayakan pengobatan kepada dokter. Pendapat lain mengenai ketakutan akan komplikasi adalah mencoba untuk mendekatkan diri kepada Tuhan. Pengalaman lain dari peserta adalah dengan hidup dengan senang tidak perlu memikirkan hal yang belum tentu terjadi.

Topik terakhir yang dibahas adalah mengenai penyesuaian gaya hidup diabetes melitus. Tidak semua mengalami kesulitan dalam penyesuaian diri. Beberapa dari peserta menyarankan untuk mengubah gaya hidup sedikit demi sedikit sesuai kemampuan. Peserta lain menyampaikan bahwa tidak terlalu membebani dirinya dengan perubahan gaya hidup dan lebih fokus pada apa yang masih dapat dikerjakan.

Berdasarkan hasil skrinning menggunakan instrumen HADS diketahui bahwa $22.2 \%$ peserta mengalami borderline depresi dan 66.1\% mengalami gangguan klinis depresi. Hal ini sesuai dengan yang dikemukakan oleh Naskar et al.(2017), yang menyebutkan bahwa prevalensi depresi pada penderita diabetes melitus antara 7\%$84 \%$. Beberapa faktor resiko terkait depresi pada penderita diabetes melitus adalah peningkatan usia, wanita, sosial ekonomi rendah dan lama mengidap $>2$ tahun (Katon, 2008). Beberapa mekanisme komorbiditas antara depresi dan diabetes melitus adalah adanya radikal bebas yang dihasilkan terkait dengan stres yang memicu penyakit diabetes melitus dan memperburuk prognosis dari diabetes melitus (Naskar et al., 20017). Penyakit diabetes melitus sendiri yang merupakan penyakit kronis dengan berbagai komplikasi dan disabilitas yang dapat sebagai stresor bagi penderitanya. Hal ini semakin menguatkan studi yang menyebutkan bahwa depresi merupakan komorbiditas masalah kesehatan jiwa terbesar pada penderita diabetes melitus (Bener, 2011).

Masalah kesehatan mental lain yang terlihat dalam hasil skrinning kali ini adalah kecemasan. Ditemukan 44\% mengalami borderline kecemasan dan $22.22 \%$ mengalami gejala klinis cemas. Selain depresi, kecemasan tercatat sebagai komorbiditas diabetes melitus yang cukup tinggi. Berdasarkan penelitian Thour et al.(2016), didapatkan 30\% pasien dengan diabetes melitus memiliki kecenderungan kecemasan. Penelitian lain menunjukkan angka yang tidak begitu berbeda yakni sebanyak $34 \%$ pasien diabetes melitus komorbid dengan kecemasan (Gul dan Bali, 2017). Beberapa faktor resiko ialah jenis kelamin, lama depresi dan jenis kepribadian (Balhara dan Sagar, 2011).

Beberapa topik permasalahan yang dibahas antara lain adalah mengenai manajemen stres. Berdasarkan penelitan Nomura et al. (2014), stres sangat berpengaruh dengan tingginya kadar gula darah. Kemampuan seseorang dalam menghadapi permasalahan kehidupan (coping mechanism) merupakan hal yang penting dalam proses adaptasi dan penerimaan penyakit kronis (Parildar et al., 2014). Coping mechanism yang tepat akan menurunkan tingkat stres sehingga menjaga kadar gula darah tetap stabil. Terdapat dua coping mechanism dalam permasalahan yakni menjauhkan masalah yang dihadapi (problem focused coping) dan mengatur respon saat menghadapi masalah (emotion focused coping). Dalam sesi diskusi swabantu telah ditawarkan dua penyelesaian yang mewakili dari problem focus coping (mengurangi aktivitas yang menambah beban pemikiran) dan emotion focused coping (mengalihkan pemikiran dengan hal lain yang lebih menyenangkan).

Permasalahan kedua pada kelompok swabantu adalah sulit tidur pada penderita diabetes melitus. Permasalahan ini merupakan komorbiditas yang cukup tinggi terjadi pada penderita diabetes melitus. 
Prevalensi gangguan tidur pada pasien diabetes dibandingkan dengan kontrol adalah $33.7 \%$ vs. $8.2 \%$, dan terbukti berbeda bermakna dengan $\mathrm{P}<0.01$ (Sridhar dan Madhu, 1994). Pasien diabetes melitus yang memiliki gangguan tidur memiliki onset diabetes melitus yang lebih muda, dan berhubungan dengan berbagai komplikasi seperti kram di malam hari, paresthesia, gula darah yang tidak terkontrol (Zhu et al., 2014). Penelitian lain menyebutkan bahwa komorbiditas diabetes melitus dan gangguan tidur dipicu oleh gangguan fisik seperti kencing di malam hari, banyak kencing, nyeri diabetes, hipertensi maupun depresi (Surani, 2015). Penelitian lain menyebutkan bahwa pengurangan waktu tidur pada pasien diabetes melitus berhubungan bermakna dengan gangguan toleransi glukosa (Gottlieb et al., 2005). Dalam kelompok swabantu, peserta telah dapat mengenali bahwa salah satu penyebab dari gangguan tidur adalah gula darah yang tidak terkontrol. Beberapa saran yang di kemukakan dalam diskusi adalah perubahan gaya hidup dan respon ketika mengalami sulit tidur. Hal ini sesuai dengan penelitian yang menyebutkan coping mechanism dapat memperbaiki gangguan tidur pada pasien diabetes melitus (Sridhar dan Madhu, 1994). Permasalahan ketiga adalah kepatuhan dalam mengkonsumsi obat. Berdasarkan penelitian Eroglue, et al.(2014), jumlah ketidakpatuhan dalam konsumsi obat diabetes melitus adalah sebanyak $70 \%$. Penyebab perilaku ketidakpatuhan minum obat adalah kurangnya motivasi dalam mengkonsumsi obat $(61.4 \%)$ dan kesulitan mengingat jadwal minum obat(55.8\%). Penyebab lain dari putus pengobatan adalah masalah ekonomi (50\%) dan jarak pasien dengan layanan pengobatan (42\%). Penelitian lain menyebutkan bahwa penyebab dari ketidakpatuhan pengobatan adalah kurangnya pengetahuan mengenai pengobatan diabetes melitus (Kakumani dan Waingankar, 2016). Pada kelompok swabantu belum ditemukan jalan keluar antar peserta untuk mengatasi permasalahan kepatuhan obat. Dibutuhkan edukasi maupun konseling mengenai pengobatan diabetes melitus untuk meningkatkan kepatuhan minum obat.

Pemasalahan keempat adalah ketakutan akan komplikasi penyakit diabetes melitus. Pada penelitian Taylor et al.(2005) ketakutan pada penderita diabetes melitus dibagi menjadi ketakutan spesifik (kebutaan, problem ginjal, sakit jantung), ketakutan pada perubahan gaya hidup, ketakutan akan hypoglikemia. Berdasarkan ketiga kelompok ketakutan diabetes, yang memiliki hubungan yang bermakna secara signifikan adalah ketakutan akan komplikasi diabetes melitus (63\%)( Sridhar \& Madhu, 1994). Beberapa saran dalam kelompok swabantu lebih menitikberatkan pada bagaimana cara menghadapi ketakutan dengan mengalihkan ketakutan dan mengikuti petunjuk dokter mengenai manajeman diabetes melitus.

Permasalah terakhir yang dibahas dalam kelompok swabatu adalah penyesuaian dengan gaya hidup. Keberhasilan dalam penyesuaian gaya hidup akan mencegah perburukan penyakit diabetes melitus (Parildar et al., 2014). Dalam kelompok swabantu dibahas mengenai target perubahan secara bertahap untuk mempermudah dalam penyesuaian terhadap perubahan gaya hidup. Namun pada penelitian Taylor et al.(2005), disampaikan bahwa ketakutan terhadap perubahan gaya hidup hanya memberikan kontribusi kecemasan minimal pada pasien diabetes melitus.

\section{KESIMPULAN}

Pada kelompok swabantu di Desa Bogoran, Trirenggo, Bantul ditemukan komorbiditas gejala klinis depresi dan cemas pada penderita diabetes. Beberapa permasalahan yang dialami oleh para penderita adalah manajemen stres, gangguan tidur, kepatuhan minum obat, ketakutan akan komplikasi dan penyesuaian gaya hidup. Kegiatan kelompok swabantu selain dapat membantu para penderita diabetes dalam menangani permasalahan yang dihadapi 
terkait dengan diabetes melitus, juga dapat memberikan rasa kebersamaan dan saling menguatkan antar penderita diabetes.

\section{DAFTAR PUSTAKA}

Anani, S. (2012). Hubungan Antara Perilaku Pengendalian Diabetes dan Kadar Glukosa Darah Pasien Rawat Jalan Diabetes Melitus (Studi Kasus di RSUD Arjawinangun Kabupaten Cirebon). Jurnal Kesehatan Masyarakat Universitas Diponegoro, 1(2), 466-478.

Ariani, Y. (2012). Pengetabuan Diabetes Melitus Dengan Kadar Gula Darah Pada Pasien Diabetes Melitus Tipe 2. Universitas Sumatra Utara, Medan.

Balhara, Y. P. S., \& Sagar, R. (2011). Correlates of anxiety and depression among patients with type 2 diabetes mellitus. Indian journal of endocrinology and metabolism, 15(Suppl1), S50.

Bener, A., OAA Al-Hamaq, A., \& E Dafeeah, E. (2011). High prevalence of depression, anxiety and stress symptoms among diabetes mellitus patients. The Open Psychiatry Journal, 5(1), 5-12.

Eroğlu, S. C.., Şensoy, F., Beydağ, K. D., \& Kiyak, M. (2014). Compliance with diabetic patients with diabetes and requirements of taking education. Procedia-Social and Behavioral Sciences, 152, 457-464.

Gottlieb, D. J., Punjabi, N. M., Newman, A. B., Resnick, H. E., Redline, S., Baldwin, C. M., \& Nieto, F. J. (2005). Association of sleep time with diabetes mellitus and impaired glucose tolerance. Archives of internal medicine, 165(8), 863-867.

Gul, D., \& Bali, K. (2017). A study of comorbidity of depression, anxiety and diabetes mellitus. International Journal of Medical and Dental Sciences, 6(2), 1513-1517.

Kakumani, K. V., \& Waingankar, P. (2016). Assessment of compliance to treatment of diabetes and hypertension amongst previously diagnosed patients from rural community of Raigad District of Maharashtra. J Assoc Physicians India, 64(12), 36-40.

Katon, W. J. (2008). The Comorbidity of Diabetes Mellitus and Depression. The American Journal of Medicine, 121 (11), S8-S15.

Kelleher, D. J. (1991). Patients learning from each other: self-help groups for people with diabetes. Journal of the Royal Society of Medicine, 84(10), 595597.

Naskar, S., Victor, R., \& Nath, K. (2017). Depression in diabetes mellitus-A comprehensive systematic review of literature from an Indian perspective. Asian journal of psychiatry, 27, 85-100.

Parildar, H., Cigerli, O., \& Demirag, N. G. (2015). Depression, coping strategies, glycemic control and patient compliance in type 2 diabetic patients in an endocrine outpatient clinic. Pakistan journal of medical sciences, 31(1), 19.

Rösen, P., Nawroth, P. P., King, G., Möller, W., Tritschler, H. J., \& Packer, L. (2001). The role of oxidative stress in the onset and progression of diabetes and its complications: a summary of a Congress Series sponsored byUNESCO-MCBN, the American Diabetes Association and the German Diabetes Society. Diabetes/metabolism research and reviews, 17(3), 189-212.

Seekles, W., van Straten, A., Beekman, A., van Marwijk, H., \& Cuijpers, P. (2011). Effectiveness of guided selfhelp for depression and anxiety disorders in primary care: a pragmatic randomized controlled trial. Psychiatry Research, 187(1-2), 113-120.

Sobol-Pacyniak, A. B., Szymczak, W., Kwarta, P., Loba, J., \& Pietras, T. (2014). Selected factors determining a way of coping with stress in type 2 diabetic patients. BioMed research international, 2014, 1-7. 
Sridhar, G. R., \& Madhu, K. (1994). Prevalence of sleep disturbances in diabetes mellitus. Diabetes research and clinical practice, 23(3), 183-186.

Surani, S., Brito, V., Surani, A., \& Ghamande, S. (2015). Effect of diabetes mellitus on sleep quality. World journal of diabetes, 6(6), 868.

Taylor, E. P., Crawford, J. R., \& Gold, A. E. (2005). Design and development of a scale measuring fear of complications in type 1 diabetes. Diabetes/metabolism research and reviews, 21(3), 264-270.

Tejada-Tayabas, L. M., \& Lugo, M. J. R. (2014). The role of mutual support groups for the control of diabetes in a Mexican City: Achievements and limitations from the patients' perspective. Health, 6(15), 1984.

Thour, A., Nagra, R., Gosal, A., Sehrawat, T., Das, S., \& Gupta, Y. (2016). Anxiety among patients with diabetes mellitus evaluated using generalized anxiety disorder 7-item scale. Journal of Social Health and Diabetes, 4(02), 133136.

Thour, A., Nagra, R., Gosal, A., Sehrawat, T., Das, S., \& Gupta, Y. (2016). Anxiety among patients with diabetes mellitus evaluated using generalized anxiety disorder 7-item scale. Journal of Social Health and Diabetes, 4(02), 133136.

Zhu, B. Q., Li, X. M., Wang, D., \& Yu, X. F. (2014). Sleep quality and its impact on glycaemic control in patients with type 2 diabetes mellitus. International Journal of Nursing Sciences, 1(3), 260265. 